\title{
Fertility Preservation Before Deployment: Oocyte and Sperm Freezing in Members of the Active Duty Military
}

\author{
Anne E. Martini, DO ${ }^{1}$ Joseph O. Doyle, MD² \\ ${ }^{1}$ Department of Reproductive Endocrinology and Infertility, Eunice \\ Kennedy Shriver National Institute of Child Health and Human \\ Development, National Institutes of Health, Bethesda, Maryland \\ 2 Shady Grove Fertility, Rockville, Maryland \\ Address for correspondence Anne E. Martini, DO, Department of \\ Reproductive Endocrinology and Infertility, Eunice Kennedy Shriver \\ National Institute of Child Health and Human Development, National \\ Institutes of Health, 10 Center Drive, Building 10, Room 8N248B, MSC \\ 1840, Bethesda, MD 20892-1840 \\ Semin Reprod Med 2019;37:232-238 \\ (e-mail: anne.e.martini@gmail.com).
}

\begin{abstract}
Keywords

- fertility preservation

- military

- deployment

Active duty military service and deployment has the potential to compromise fertility through combat-related genitourinary injury, gonadotoxic exposures, and physical separation from a partner. Despite a growing interest among the military community as well as promising efficacy and safety data, fertility preservation remains an uncovered benefit for active duty soldiers. In 2016, the Pentagon proposed a program that would cover oocyte and sperm cryopreservation for any member of the active duty military desiring its use. Regrettably, that funding was not secured and predeployment fertility preservation remains an out-of-pocket expense. Today, advocacy groups, nonfor-profit organizations, and physicians remain vigilant in their attempts to drive another government initiative through Congress. While activism continues, it is important to stress the value of fertility preservation counseling in soldiers' predeployment preparation and military family planning.
\end{abstract}

There are a multitude of factors that have the ability to influence the reproductive capacity of a man or a woman. These include various medical conditions or syndromes, gonadotoxic therapy, gonadal injury, or age-related fertility decline. Over the last decade, there has been an increase in utilization of fertility preservation services for nonmedical indications in both men and women, including an elective interest in delayed childbearing. ${ }^{1}$ Though pregnancy outcome data are continuing to evolve as more patients return to use their stored gametes, the reports that are currently available for both cryopreserved oocytes and sperm are encouraging. $^{2-4}$

The American Society of Clinical Oncology (ASCO) and the American Society for Reproductive Medicine (ASRM) stress the importance of discussing fertility preservation in patients undergoing gonadotoxic therapies. ${ }^{5,6}$ Despite these guidelines and a strong desire by patients to be informed of the fertility preservation options available, referrals to reproductive specialists are not part of routine practice in all centers. ${ }^{5}$ With fertility preservation indications extending beyond the walls of oncology, it is likely that providers in other disciplines also fall short in recommending fertility preservation counseling to those who may be at risk for fertility compromise.

Military deployment presents a multifaceted threat to both male and female fertility due to the reproductive delay posed by physical separation from a partner and the risk of gonadal injury or gonadotoxic exposure while in combat. ${ }^{7}$ Though few options exist for gamete retrieval in injured soldiers, available techniques are suboptimal when compared with elective fertility preservation in healthy, uninjured gonads. ${ }^{8,9}$ The Department of Veterans Affairs (VA) provides financial assistance for assisted reproductive technology (ART), including gamete cryopreservation, for veterans with a service-connected disability or medical conditions that render them unable to naturally reproduce. ${ }^{10}$ Conversely, the U.S. Department of Defense (DoD)
Issue Theme Reproductive Health Needs of the Military and Veterans: Part 3; Guest Editors, Alicia Y. Christy, MD, MHSCR, FACOG and Gilbert L. Mottla, MD
Copyright $\odot 2019$ by Thieme Medical Publishers, Inc., 333 Seventh Avenue, New York, NY 10001, USA. Tel: +1(212) 760-0888. ISSN 1526-8004. 
does not provide coverage for ART or cryopreservation of gametes for active duty men and women in any scenario, including prior to deployment. Despite an attempted initiative in 2016, limited progress has been made in securing funds to cover these services. As it currently stands, the option to pursue and finance predeployment fertility preservation is a burden borne by the soldier. As fertility preservation techniques become increasingly effective and rates of genitourinary (GU) injury sustained during deployment remain relatively high, strong consideration should be given to providing referrals for fertility preservation counseling in active duty military members predeployment. This article will summarize the available techniques and success rates for male and female fertility preservation; provide an overview of the fertility challenges faced by those in active duty; and comprehensively review the past, present, and hopeful future of U.S. policies regarding fertility preservation as a covered service for members of the active duty military.

\section{Fertility Preservation: Overview of Techniques, Success Rates, and Utilization}

\section{Female Fertility Preservation}

A woman's reproductive lifespan is entirely dependent on the number of oocytes with which she is born. A decline in oocyte quantity and quality occurs gradually, but begins to accelerate after the age of 32 and even more quickly after the age of $37 .{ }^{11}$ Historically, fertility preservation techniques were primarily sought by women undergoing gonadotoxic therapy as a means of safeguarding their reproductive potential for use following treatment. As the efficacy of oocyte cryopreservation began to improve, there was a parallel rise in the population of women pursuing treatment to delay childbearing until later in their reproductive years. Elective fertility preservation, with the goal of circumventing this natural ovarian aging process, now outpaces medically indicated treatment in terms of the number of cycles performed annually in the United States. ${ }^{12-14}$

The preferred technique for fertility preservation in females involves the cryopreservation of metaphase II oocytes obtained through the process of controlled ovarian stimulation. If needed for procreation, these oocytes are later thawed and inseminated to create embryos for use during an in vitro fertilization (IVF) cycle. Oocyte cryopreservation was considered an experimental therapy until 2012 when ASRM issued a document which effectively lifted its experimental label. ${ }^{12}$ Prior to that time, cryopreservation of embryos obtained through IVF was the only nonexperimental method to preserve a woman's fertility. As embryo cryopreservation is limited to those women with a male partner or a willingness to inseminate her eggs with donor sperm, oocyte cryopreservation has opened avenues to more women seeking cryopreservation for both elective and nonelective indications. ${ }^{15}$ Other techniques for female fertility preservation such as in vitro maturation of immature oocytes and ovarian tissue cryopreservation are still considered experimental, but are available at some centers for prepubertal girls or women with aggressive or hormonesensitive malignancies who cannot undergo standard fertility preservation methods. ${ }^{1}$ Ovarian suppression with gonadotro- pin-releasing hormone agonists has been demonstrated to reduce the rate of chemotherapy-induced premature ovarian insufficiency, but does not unequivocally guarantee future pregnancy success. ${ }^{16}$

Oocyte cryopreservation was historically performed using slow-freezing techniques. Slow-freezing, developed in the 1970s, utilizes a programmable device which cools the tissue at a slow rate $\left(0.3-2.0^{\circ} \mathrm{C} /\right.$ minute), thereby maximizing cellular dehydration and minimizing the formation of intracellular ice crystals that could compromise tissue survival. An alternative technique called vitrification has been used in other fields at least as long as slow-freezing, but was not applied successfully to human oocytes until the last decade. Vitrification allows for ultra-rapid and effective cooling of tissue $\left(>20,000^{\circ} \mathrm{C} /\right.$ minute $)$ through the use of high concentrations of cryoprotectants and high temperature gradients. ${ }^{17}$ Though slow-freezing protocols have improved since their inception, recent data demonstrates that vitrification of oocytes results in higher post-thaw survival, embryonic development, and pregnancy rates when compared with slow-freezing. ${ }^{18-22}$

The performance of cryopreserved oocytes continues to improve as centers refine and perfect their cryopreservation and thaw methods. ${ }^{12}$ A recent meta-analysis of five randomized controlled trials demonstrated that fertilization and pregnancy rates were similar between fresh and vitrified/ warmed oocytes used for IVF with intracytoplasmic sperm injection (ICSI). ${ }^{23}$ The largest randomized controlled trial comparing fresh versus vitrified donor oocytes found that both groups were statistically similar in terms of fertilization rates as well as implantation and clinical pregnancy rates per embryo transferred $\left(74,61\right.$, and $55 \%$, respectively). ${ }^{24}$ Due to declining oocyte quality with increasing age, pregnancy rates will vary based on the age at which the oocytes were retrieved. Doyle et al estimated probabilities of live birth in patients who pursued elective oocyte cryopreservation according to the number of mature oocytes retrieved and age at the time of retrieval. For women aged $<38$, cryopreserving 15 to 20 mature oocytes gave an approximate 70 to $80 \%$ chance of at least one future live birth. Comparatively, women aged 38 to 40 cryopreserving 25 to 30 mature oocytes led to an estimated 65 to $75 \%$ chance of at least one future live birth. ${ }^{2}$ Given that oocyte quantity also declines with age, obtaining the recommended number of oocytes to maximize chances of future live birth may not always be feasible. Additionally, as the majority of published outcome data comes from large centers proficient in oocyte cryopreservation and thaw techniques, the results may not be entirely generalizable to all clinics.

Oocyte cryopreservation is widely accepted by the public across a variety of freezing indications. Results of a national internet survey of both men and women demonstrated that $89 \%$ of respondents supported oocyte cryopreservation for cancer, $72 \%$ for delayed childbearing, and $63 \%$ for being unpartnered. ${ }^{25}$ Another survey study of U.S. women pursuing elective cryopreservation reported women felt they had improved their reproductive future and felt empowered by the process. ${ }^{26}$ Furthermore, studies evaluating the cost-effectiveness of elective egg freezing demonstrated reduced live 
birth costs when eggs were frozen prior to age $38 .^{27}$ Despite its public support and cost-effectiveness, it is often cost prohibitive. A cross-sectional survey study of U.S. women of childbearing age demonstrated that those interested in egg freezing would only be willing to pay $\$ 3,811.55$, which is significantly less than what clinics standardly charge. ${ }^{28}$ Even with some large companies funding elective egg freezing for their employees and six U.S. states passing laws covering fertility preservation for patients at risk for iatrogenic infertility, the majority of women are still paying for this service out-ofpocket. ${ }^{29}$ Taking this data together, it is important to continue to advocate for more comprehensive fertility preservation coverage across all indications.

\section{Male Fertility Preservation}

Sperm cryopreservation is the preferred method for fertility preservation in postpubertal males. While sperm banking is most commonly employed for those with medical conditions or therapies that may compromise spermatogenesis, it is also becoming more frequently utilized for nononcologic indications. ${ }^{7}$ Techniques for sperm cryopreservation are well established and typically involve a combination of both slow-cooling and rapid-freezing methods with glycerol as the primary cryoprotectant. ${ }^{30}$ Sperms for cryopreservation are most commonly obtained through ejaculation via masturbation, though penile vibratory stimulation or electroejaculation has also been utilized in men with anejaculation. ${ }^{1,30}$ In men with obstructive azoospermia or who are unable to produce an ejaculated sample, sperm can be surgically aspirated from the vas deferens, epididymis, or testicle via a percutaneous or open procedure. ${ }^{31}$ In male soldiers injured in combat, seminal vesicle aspiration has also been described with encouraging success rates. ${ }^{8}$ Testicular tissue cryopreservation is offered at select institutions for prepubertal male patients but is still considered an experimental technique. ${ }^{32}$

Pregnancies using cryopreserved sperm are achieved through the use of ART including intrauterine insemination (IUI), IVF, and ICSI. Pregnancy rates using cryopreserved sperm have increased accordingly with advancements in these technologies, particularly ICSI in which a single live spermatozoa is required for insemination of the oocyte. ${ }^{1}$ In a study of 272 men who pursued fertility preservation prior to cancer treatment, live birth rates with IVF-ICSI were reported to be $62.1 \%$ which was higher than the males without cancer undergoing the same treatment. ${ }^{4}$ These rates are similar to other published reports. ${ }^{32,33}$ Similarly, studies comparing the use of fresh and cryopreserved sperm in ART have demonstrated equivalent performance. ${ }^{34,35}$ Additionally, cryopreserved sperm can be safely utilized decades later with relatively no impact on clinical success rates. ${ }^{36}$ The longest durations of sperm cryopreservation resulting in live births from IUI and IVF are 28 and 40 years, respectively. ${ }^{37,38}$ To date, there have been no adverse outcomes reported in offspring conceived through the use of cryopreserved sperm. ${ }^{32}$

The marked benefits of male fertility preservation have been demonstrated to extend beyond the physical ability to achieve parenthood, particularly reflected again in the cancer literature. Male factor infertility has been cited to be one of the most troubling side effects of anticancer treatment. ${ }^{39}$ Adolescent and adult cancer patients who choose to bank sperm prior to treatment have demonstrated improved psychological health and postsurvival fatherhood. ${ }^{40,41}$ Evidence from UK servicemen who experienced GU injury suggested that men in whom fertility persisted had better injury recovery and quality of life. ${ }^{42}$

Despite the encouraging success rates and multiple benefits to be gained, very few men actually pursue fertility preservation when appropriate. Barriers to fertility preservation include lack of interest, cost of freezing and storage, and most strikingly, not being discussed or offered by their provider. ${ }^{43} \mathrm{~A}$ recent study of male cancer patients found that only $29 \%$ of patients received fertility counseling and $11 \%$ attempted sperm banking. ${ }^{44}$ Though cost is not the most significantly cited obstacle for men who decline fertility preservation, the fees are not negligible. The cost of sperm banking varies across the United States, but most commonly includes a $\$ 1,000$ initial processing cost with yearly storage fees ranging from $\$ 300$ to $\$ 500 .{ }^{45}$ These cost estimates do not factor in the fees associated with ART if needing to utilize their cryopreserved sperm. Similar to oocyte cryopreservation, sperm banking is infrequently covered by insurance, regardless of the indication. In a qualitative analysis by Sonnenburg et al, multiple patients noted that if the cost were covered by insurance, that may have changed their decision to bank. ${ }^{43}$ Taken together, these findings stress the importance of timely communication between providers and patients regarding health and occupational hazards that may impact their fertility as well as the benefits associated with sperm cryopreservation.

\section{Gamete Utilization}

Reported rates of gamete utilization after fertility preservation in the general population have been variable and are likely underestimated due to the samples that remain in storage..$^{33,46}$ Machen et al published a study in 2018 that set to examine the utilization rates and outcomes of cryopreserved sperm in their general male population based on indication for storage. For the 1,442 samples frozen over a 27-year period, total sample utilization rate was $19.3 \%$. Notably, of all cryopreserved samples, $5.5 \%$ was cryopreserved prior to military deployment. Military men had a sample utilization rate of $22.8 \%$ and the majority of the samples tended to be used within the first year of storage. However, the majority of these men were part of an infertile couple who happened to be deploying during the time of their treatment. Therefore, these utilization rates do not accurately reflect the male population electively freezing sperm prior to deployment. Additionally, this study did not discern whether these men experienced further fertility compromise while in combat which prompted their use of the samples. ${ }^{47}$

A study by Cobo et al in 2016 assessed utilization rates in 1,468 women who pursued fertility preservation for nononcologic indications from 2007 to 2015. In that time interval, 137 women (9.3\%) returned to use their frozen eggs with a mean freeze-to-thaw interval of 2.2 years. ${ }^{3} \mathrm{~A}$ study published a year later by Hammarberg et al examined a smaller cohort of women over a longer time period. Of their 193 patients, only 
6 returned to use their oocytes (3.1\%); however $21 \%$ reported intent to use. ${ }^{48}$ It would be anticipated that utilization rates may be higher in a population where the probability of GU compromise is increased above that of the general population. Future studies examining the utilization of cryopreserved oocytes in active duty military women will be important to pursue.

\section{Active Duty Military: Reproductive Challenges and Considerations}

Active duty military members face multiple obstacles that may impact their future ability to reproduce. The most notable evidence-based risks are the age and marital status at the time of deployment, the risk for gonadal injury in combat, and potential risks of infertility. Women who are found to be pregnant while deployed are required to be evacuated from combat areas. In understanding the ability of pregnancy to impact troop readiness, a woman may elect to delay childbearing beyond her original family planning goals. $^{49}$ If a decision to pursue fertility preservation is made, plans for gamete disposition should be thoroughly discussed. Military members should be extensively counseled on their various reproductive risks prior to deployment and have a low threshold for fertility preservation counseling.

\section{Age and Marital Status at the Time of Deployment}

There are more than 1 million enlisted members and officers of the active duty military, the majority of which are men and women of reproductive age. ${ }^{7,49-51}$ The U.S. DoD data in 2010 showed that average age of military personnel deployed in Operation Iraqi Freedom and Operation Enduring Freedom was 33.4 years with $45 \%$ between ages of 25 and 34 years. Sixty percent were married at the time of deployment, but $51 \%$ did not have children. ${ }^{52}$ Per the most recent military demographic profile in 2017, the average age of active duty enlisted members and officers was 28.3 years. Approximately half of all active duty members were 25 years of age or younger and this age distribution has remained relatively stable over the last decade. Additionally, $42.5 \%$ of active duty members reported never being married and $61.6 \%$ did not have children. Women currently comprise $16.2 \%$ of all active duty personnel. ${ }^{51}$ As the number of women joining active duty service continues to increase each year, it is important to provide them with education on age-related fertility decline and the impact that delayed childbearing may have on future reproductive success. ${ }^{53}$

\section{Risk of Combat-Related Genitourinary Injury}

Active duty men and women entering combat are at risk for GU injury that may compromise future fertility. A dramatic rise in the rate of GU injury was observed during the U.S. war efforts with Iraq and Afghanistan, primarily due to the heavy use of ground-based explosive devices. ${ }^{54,55}$ Soldiers encountering these ground explosives often experienced dismounted complex blast injuries, a characteristic injury pattern involving multi-extremity damage or amputations, pelvic fractures, and genital/perineal injury. ${ }^{56}$ With the advancements in emergency combat care, these historically fatal complex blast injuries became survivable, but often leaving the soldiers with significant genital and reproductive morbidities. ${ }^{54}$ While the majority of service members experiencing GU injury are men (98.5\%), an increasing number of women are entering combat zones and experiencing injuries at similar rates as their male counterparts. $^{50}$

The largest review of military GU injuries was published at the conclusions of Operation Iraqi Freedom and Operation Enduring Freedom in 2017 by Janak et al. ${ }^{55}$ Over the 12 years and 30,000 injury codes analyzed through the Department of Defense Trauma Registry (DoDTR), 1,462 (5.3\%) service members were reported to have sustained one or more GU injuries. Of these soldiers, $1,000(73.2 \%)$ had one or more injury to the external genitalia and 502 (36.7\%) were classified as severe GU injury. To date, there have been no published long-term follow-up studies evaluating future reproductive potential or gonadal function in these service members.

A survey study of UK servicemen who sustained GU injuries in combat reported that experiencing genital injury was more devastating than lower limb amputations. Additionally, their psychological outcomes were improved when their fertility status was known and revealed to them at an early stage. ${ }^{9}$ Future directions have been aimed at improving personal protective equipment for both men and women in combat zones which has shown some promise in one observational study. ${ }^{57}$ As mentioned previously, options for sperm preservation are available for select injured soldiers; however, there are currently no available means of pursuing female fertility preservation in the setting of combat injury. ${ }^{8}$

\section{Risk for Infertility}

The National Health Study for a New Generation of U.S. Veterans, a survey study of veterans who served in Operation Enduring Freedom/Operation Iraqi Freedom, reported a lifetime prevalence of infertility for servicemen and women of 13.8 and $15.8 \%$, respectively. After adjusting for confounding variables, they found similar rates of infertility between men and women; however, they noted that women veterans were more likely to seek care for infertility treatment. ${ }^{58}$ Additional studies have demonstrated associations between elevated rates of lifetime sexual assault and infertility or lack of infertility evaluations in female veterans. ${ }^{59}$ Given the varied definitions used for surveying the population for prevalence of infertility, direct comparisons between the military and nonmilitary populations are difficult. Reports of various exposures among military personnel and associations with infertility are also conflicting and have multiple limitations. ${ }^{60,61}$ At this time, more research is necessary to establish a causal relationship between combat exposures and infertility.

\section{Posthumous Reproduction}

Active duty military members and their families who elect to pursue predeployment fertility preservation should consider the disposition of their gametes in the event the soldier dies in combat. Similar to cancer patients undergoing fertility 
preservation prior to treatment, an advanced directive for disposition of the gametes should be defined. Posthumous reproduction, or the use of a deceased person's gametes for ART, is permitted by law if the deceased has given explicit directions for them to do so. ${ }^{62}$ In a study by Pastuszak et al of 364 men undergoing sperm banking prior to cancer treatment or for the management of infertility, $85.9 \%$ consented to posthumous sperm use. ${ }^{63}$ As this represents complicated and difficult decision making, proper counseling of soldiers at the time of fertility preservation is critical.

\section{Past, Present, and Future of Fertility Preservation Coverage for Active Duty Military}

Historically, there have been no formal policies through the active duty military health care program (TRICARE) that provide coverage for ART or gamete cryopreservation. ${ }^{7}$ In 2016, the DoD proposed a pilot program entitled the "Force of the Future" which included sperm and oocyte cryopreservation as a covered benefit for active duty military set to deploy. In addition to revising parental leave policies and child care services for military personnel, this program's $\$ 38$ million request intended to fund initial cryopreservation costs and storage fees for up to 2 years. ${ }^{7}$ The goal of the Defense Secretary Ashton Carter was to provide "peace of mind" for deploying troops and "greater flexibility" for family building upon their return, particularly for those who suffered sterilizing combat injuries. ${ }^{64}$ Unfortunately, this proposal fell through in Congress in 2017 and there have been no significant attempts to revive it.

Criticisms of the initiative included conservative ideologies and issues with the ART that would be required to use said gametes. ${ }^{65}$ The primary controversies that continue to prevent policy change are notably all definable and resolvable issues: storage duration limits, storage fees, and legal ownership of gametes if a soldier dies in combat. ${ }^{8}$ Active duty military personnel have the option to pursue predeployment fertility preservation through civilian or military centers at discounted rates, but there is still significant out-of-pocket cost. There are non-for-profit organizations like the Bob Woodruff Foundation that aid in covering costs, but there is little data on how often military personnel choose to utilize these programs for fertility preservation.

There are no published studies evaluating how strongly active duty service members value discussions regarding their reproductive risks, access to fertility services, or the ability to bear biological children as it relates to their deployment. A conference sponsored by the Bob Woodruff Foundation in 2011 titled "Intimacy after Injury" offered personal accounts from injured soldiers on the psychological impact of becoming infertile as a result of their service. One spouse of an injured soldier recounted, "When they tell you that you will never have children, you feel completely violated. Why didn't somebody talk to us about banking sperm?"66 Survey studies in female veterans have demonstrated that they express a strong desire for reproductive life planning. ${ }^{67}$ A study evaluating women veterans' reproductive preferences and experiences with VA women's health services concluded that women veterans desired more from their reproductive care and were interested in expanded access to advanced fertility services. One woman was quoted saying, “...I can essentially say that I gave my reproductive years to the Marine Corps. And those are the years you can serve. We serve during our fertile years and we sacrifice.... The VA should probably address that part of womanhood and have that understanding." 68 Further studies in active duty servicemen and women are essential to delineate the attitudes toward advanced reproductive services and whether they would choose to pursue fertility preservation as part of a covered benefit program.

While awaiting future policy change, active duty members of the military should be counseled on the risks, benefits, success rates, cost, and ethical implications of pursuing fertility preservation to make an informed decision prior to deployment. Once a program supporting clinical care is in place, it will require effort by the DoD to ensure soldiers are properly educated on such programming, cryopreservation storage limits and ethical considerations. ${ }^{42}$

\section{Conclusion}

Fertility preservation in men and women is safe, successful, and done routinely in the cases of planned gonadotoxic medical treatments. If provided as a covered benefit for active duty soldiers, it is likely that larger numbers would take part in predeployment gamete storage, allowing them to safely secure a portion of their reproductive liberty while risking their lives to protect our country. Senator Patty Murray addressed the Senate with this statement after the "Force of the Future" initiative failed to be approved in 2017: "It's hard to imagine any of my colleagues standing up to say that men and women willing to make the ultimate sacrifices for their country - for all of us should be denied a shot at their dream of a family." ${ }^{65}$ Without a federal policy in place, providers caring for servicemen and women must take it upon themselves to provide education on the reproductive risks associated with deployment, the various options for fertility preservation, and financial assistance opportunities available to pursue gamete cryopreservation.

Conflict of Interest

None.

\section{Acknowledgments}

This research did not receive any external funding.

\section{References}

1 Martinez F; International Society for Fertility PreservationESHRE-ASRM Expert Working Group. Update on fertility preservation from the Barcelona International Society for Fertility Preservation-ESHRE-ASRM 2015 expert meeting: indications, results and future perspectives. Fertil Steril 2017;108(03): 407-415.e11

2 Doyle JO, Richter KS, Lim J, Stillman RJ, Graham JR, Tucker MJ. Successful elective and medically indicated oocyte vitrification and warming for autologous in vitro fertilization, with predicted birth probabilities for fertility preservation according to number of cryopreserved oocytes and age at retrieval. Fertil Steril 2016; 105(02):459-66.e2 
3 Cobo A, García-Velasco JA, Coello A, Domingo J, Pellicer A, Remohí J. Oocyte vitrification as an efficient option for elective fertility preservation. Fertil Steril 2016;105(03):755-764.e8

4 García A, Herrero MB, Holzer H, Tulandi T, Chan P. Assisted reproductive outcomes of male cancer survivors. J Cancer Surviv 2015;9(02):208-214

5 Ethics Committee of the American Society for Reproductive Medicine. Electronic address: ASRM@asrm.org. Fertility preservation and reproduction in patients facing gonadotoxic therapies: an Ethics Committee opinion. Fertil Steril 2018;110(03):380-386

6 Lee SJ, Schover LR, Partridge AH, et al; American Society of Clinical Oncology. American Society of Clinical Oncology recommendations on fertility preservation in cancer patients. J Clin Oncol 2006;24(18):2917-2931

7 Yang H, Ramstein J, Smith J. Non-oncologic indications for male fertility preservation. Curr Urol Rep 2019;20(09):51

8 Healy MW, Yauger BJ, James AN, Jezior JR, Parker P, Dean RC. Seminal vesicle sperm aspiration from wounded warriors. Fertil Steril 2016;106(03):579-583

9 Lucas PA, Page PR, Phillip RD, Bennett AN. The impact of genital trauma on wounded servicemen: qualitative study. Injury 2014; 45(05):825-829

10 VHA Directive. 1332 Infertility Evaluation and Treatment. 2017. Available at: https://webcache.googleusercontent.com/search?q= cache:9JTbctfGprUJ:https://www.va.gov/vhapublications/ViewPublication.asp\%3Fpub_ID\%3D5431+\&cd=1\&hl=en\&ct=clnk\&gl=us\& client=safari. Accessed October 31, 2019

11 American College of Obstetricians and Gynecologists. ACOG Committee Opinion. Age-related fertility decline. Obstet Gynecol 2008;112(2, Pt 1):409-411

12 Practice Committees of American Society for Reproductive Medicine; Society for Assisted Reproductive Technology. Mature oocyte cryopreservation: a guideline. Fertil Steril 2013;99(01):37-43

13 Goldman KN. The evolution of oocyte cryopreservation (OC): longitudinal trends at a single center. Fertil Steril 2014;102: e164-e165

14 Mucowski S. Current utilization status of cryopreserved oocytes in the United States. Fertil Steril 2014;101:e31-e32

15 ACOG. ACOG: Committee Opinion No. 584: oocyte cryopreservation. Obstet Gynecol 2014;123(01):221-222

16 Del Mastro L, Ceppi M, Poggio F, et al. Gonadotropin-releasing hormone analogues for the prevention of chemotherapy-induced premature ovarian failure in cancer women: systematic review and meta-analysis of randomized trials. Cancer Treat Rev 2014;40 (05):675-683

17 Chian RC, Wang Y, Li YR. Oocyte vitrification: advances, progress and future goals. J Assist Reprod Genet 2014;31(04):411-420

18 Parmegiani L, Bertocci F, Garello C, Salvarani MC, Tambuscio G, Fabbri R. Efficiency of human oocyte slow freezing: results from five assisted reproduction centres. Reprod Biomed Online 2009; 18(03):352-359

19 Oktay K, Cil AP, Bang H. Efficiency of oocyte cryopreservation: a meta-analysis. Fertil Steril 2006;86(01):70-80

20 Smith GD, Serafini PC, Fioravanti J, et al. Prospective randomized comparison of human oocyte cryopreservation with slow-rate freezing or vitrification. Fertil Steril 2010;94(06):2088-2095

21 Gook DA, Edgar DH. Human oocyte cryopreservation. Hum Reprod Update 2007;13(06):591-605

22 Rienzi L, Gracia C, Maggiulli R, et al. Oocyte, embryo and blastocyst cryopreservation in ART: systematic review and meta-analysis comparing slow-freezing versus vitrification to produce evidence for the development of global guidance. Hum Reprod Update 2017;23(02):139-155

23 Cobo A, Diaz C. Clinical application of oocyte vitrification: a systematic review and meta-analysis of randomized controlled trials. Fertil Steril 2011;96(02):277-285

24 Cobo A, Meseguer M, Remohí J, Pellicer A. Use of cryobanked oocytes in an ovum donation programme: a prospective, randomized, controlled, clinical trial. Hum Reprod 2010;25(09): 2239-2246

25 Lewis EI, Missmer SA, Farland LV, Ginsburg ES. Public support in the United States for elective oocyte cryopreservation. Fertil Steril 2016;106(05):1183-1189

26 Hodes-Wertz B, Druckenmiller S, Smith M, Noyes N. What do reproductive-age women who undergo oocyte cryopreservation think about the process as a means to preserve fertility? Fertil Steril 2013;100(05):1343-1349

27 Devine K, Mumford SL, Goldman KN, et al. Baby budgeting: oocyte cryopreservation in women delaying reproduction can reduce cost per live birth. Fertil Steril 2015;103(06):1446-53.e1, 2

28 Milman LW, Senapati S, Sammel MD, Cameron KD, Gracia C. Assessing reproductive choices of women and the likelihood of oocyte cryopreservation in the era of elective oocyte freezing. Fertil Steril 2017;107(05):1214-1222.e3

29 ASRM. New York Becomes Tenth State to Require Coverage of IVF and Sixth State to Require Coverage for Fertility Preservation for Certain Patients. 2019;22. Available at: https://www.asrm.org/ news-and-publications/news-and-research/press-releases-andbulletins/new-york-becomes-tenth-state-to-require-coverageof-ivf-and-sixth-state-to-require-coverage-for-fertility-preservation-for-certain-patients/. Accessed October 4, 2019

30 Abram McBride J, Lipshultz LI. Male fertility preservation. Curr Urol Rep 2018;19(07):49

31 Shin DH, Turek PJ. Sperm retrieval techniques. Nat Rev Urol 2013; 10(12):723-730

32 Picton HM, Wyns C, Anderson RA, et al; ESHRE Task Force On Fertility Preservation In Severe Diseases. A European perspective on testicular tissue cryopreservation for fertility preservation in prepubertal and adolescent boys. Hum Reprod 2015;30(11): 2463-2475

33 van Casteren NJ, van Santbrink EJ, van Inzen W, Romijn JC, Dohle GR. Use rate and assisted reproduction technologies outcome of cryopreserved semen from 629 cancer patients. Fertil Steril 2008; 90(06):2245-2250

34 Habermann H, Seo R, Cieslak J, Niederberger C, Prins GS, Ross L. In vitro fertilization outcomes after intracytoplasmic sperm injection with fresh or frozen-thawed testicular spermatozoa. Fertil Steril 2000;73(05):955-960

35 Levron J, Madgar I, Shefi S, et al. IVF outcome with cryopreserved testicular sperm. Andrologia 2011;43(01):48-51

36 Huang C, Lei L, Wu HL, et al. Long-term cryostorage of semen in a human sperm bank does not affect clinical outcomes. Fertil Steril 2019;112(04):663-669.e1

37 Feldschuh J, Brassel J, Durso N, Levine A. Successful sperm storage for 28 years. Fertil Steril 2005;84(04):1017

38 Szell AZ, Bierbaum RC, Hazelrigg WB, Chetkowski RJ. Live births from frozen human semen stored for 40 years. J Assist Reprod Genet 2013;30(06):743-744

39 Johnson MD, Cooper AR, Jungheim ES, Lanzendorf SE, Odem RR, Ratts VS. Sperm banking for fertility preservation: a 20-year experience. Eur J Obstet Gynecol Reprod Biol 2013;170(01): 177-182

40 Saito K, Suzuki K, Iwasaki A, Yumura Y, Kubota Y. Sperm cryopreservation before cancer chemotherapy helps in the emotional battle against cancer. Cancer 2005;104(03):521-524

41 Edge B, Holmes D, Makin G. Sperm banking in adolescent cancer patients. Arch Dis Child 2006;91(02):149-152

42 Dean WK, Caplan AL, Parent B. Military genitourinary trauma: policies, implications, and ethics. Hastings Cent Rep 2016;46(06): $10-13$

43 Sonnenburg DW, Brames MJ, Case-Eads S, Einhorn LH. Utilization of sperm banking and barriers to its use in testicular cancer patients. Support Care Cancer 2015;23(09):2763-2768

44 Grover NS, Deal AM, Wood WA, Mersereau JE. Young men with cancer experience low referral rates for fertility counseling and sperm banking. J Oncol Pract 2016;12(05):465-471 
45 Nahata L, Cohen LE, Yu RN. Barriers to fertility preservation in male adolescents with cancer: it's time for a multidisciplinary approach that includes urologists. Urology 2012;79(06):1206-1209

46 Ben-Rafael Z. The dilemma of social oocyte freezing: usage rate is too low to make it cost-effective. Reprod Biomed Online 2018;37 (04):443-448

47 Machen GL, Harris SE, Bird ET, et al. Utilization of cryopreserved sperm cells based on the indication for storage. Investig Clin Urol 2018;59(03):177-181

48 Hammarberg K, Kirkman M, Pritchard N, et al. Reproductive experiences of women who cryopreserved oocytes for non-medical reasons. Hum Reprod 2017;32(03):575-581

49 Krulewitch CJ. Reproductive health of active duty women in medically austere environments. Mil Med 2016;181(09):1166

50 Zephyrin LC. Reproductive health management for the care of women Veterans. Obstet Gynecol 2016;127(02):383-392

512017 Demographics Profile of the Military Community. 2017. Available at: https://www.militaryonesource.mil/reports-andsurveys/demographic-profiles. Accessed August 31, 2019

52 Returning home from Iraq and Afghanistan: assessment of readjustment needs of veterans, service members, and their families. Mil Med 2014;179(10):1053-1055

53 Committee on Health Care for Underserved Women, American College of Obstetricians and Gynecologists. Committee Opinion No. 547: Health care for women in the military and women veterans. Obstet Gynecol 2012;120(06):1538-1542

54 Balzano FL, Hudak SJ. Military genitourinary injuries: past, present, and future. Transl Androl Urol 2018;7(04):646-652

55 Janak JC, Orman JA, Soderdahl DW, Hudak SJ. Epidemiology of genitourinary injuries among male U.S. service members deployed to Iraq and Afghanistan: early findings from the Trauma Outcomes and Urogenital Health (TOUGH) Project. J Urol 2017; 197(02):414-419

56 Cannon JW, Hofmann LJ, Glasgow SC, et al. Dismounted complex blast injuries: a comprehensive review of the modern combat experience. J Am Coll Surg 2016;223(04):652-664.e8

57 Oh JS, Do NV, Clouser M, et al. Effectiveness of the combat pelvic protection system in the prevention of genital and urinary tract injuries: an observational study. J Trauma Acute Care Surg 2015; 79(04, Suppl 2):S193-S196
58 Katon J, Cypel Y, Raza M, et al. Self-reported infertility among male and female veterans serving during Operation Enduring Freedom/ Operation Iraqi Freedom. J Womens Health (Larchmt) 2014;23 (02):175-183

59 Ryan GL, Mengeling MA, Booth BM, Torner JC, Syrop CH, Sadler AG. Voluntary and involuntary childlessness in female veterans: associations with sexual assault. Fertil Steril 2014;102(02):539-547

60 Schrader SM, Langford RE, Turner TW, et al. Reproductive function in relation to duty assignments among military personnel. Reprod Toxicol 1998;12(04):465-468

61 Velez de la Calle JF, Rachou E, le Martelot MT, Ducot B, Multigner L, Thonneau PF. Male infertility risk factors in a French military population. Hum Reprod 2001;16(03):481-486

62 Ethics Committee of the American Society for Reproductive Medicine. Electronic address: ASRM@asrm.org; Ethics Committee of the American Society for Reproductive Medicine. Posthumous retrieval and use of gametes or embryos: an Ethics Committee opinion. Fertil Steril 2018;110(01):45-49

63 Pastuszak AW, Lai WS, Hsieh TC, Lipshultz LI. Posthumous sperm utilization in men presenting for sperm banking: an analysis of patient choice. Andrology 2013;1(02):251-255

64 Kime P. Military's new fertility benefit will let troops freeze their sperm and eggs. Military Times. 2016. Available at: https://www. militarytimes.com/pay-benefits/military-benefits/health-care/ 2016/01/29/military-s-new-fertility-benefit-will-let-troopsfreeze-their-sperm-and-eggs/. Accessed September 7, 2019

65 R H. GOP objection kills Senate funding for military fertility program. McClatchy DC Bureau. Available at: https://www.mcclatchydc.com/ news/politics-government/congress/article83811887.html. Accessed September 7, 2019

66 Bob Woodruff Foundation. Intimacy after Injury Symposium. Available at: https://bobwoodrufffoundation.org/wp-content/uploads/ 2016/10/Intimacy-After-Injury-Report.pdf. Accessed September 7, 2019

67 Callegari LS, Borrero S, Reiber GE, et al. Reproductive life planning in primary care: a qualitative study of women Veterans' perceptions. Womens Health Issues 2015;25(05):548-554

68 Mattocks KM, Nikolajski C, Haskell S, et al. Women veterans' reproductive health preferences and experiences: a focus group analysis. Womens Health Issues 2011;21(02):124-129 